\title{
The therapeutic effectiveness of using visual art modalities with the bereaved: a systematic review
}

This article was published in the following Dove Press journal:

Psychology Research and Behavior Management

\section{Rachel E Weiskittle \\ Sandra E Gramling}

Department of Clinical Psychology, Virginia Commonwealth University, Richmond, VA, USA
Correspondence: Rachel E Weiskittle Department of Clinical Psychology, Virginia Commonwealth University, 806 West Franklin Street, PO Box 842018, Richmond, VA 23284-2018, USA

$\mathrm{Tel}+$ I 804828 I I 93

Fax +l 8048282237

Email weiskittlere@vcu.edu

\begin{abstract}
Bereaved individuals are increasingly considered at risk for negative psychological and physiological outcomes. Visual art modalities are often incorporated into grief therapy interventions, and clinical application of art therapy techniques with the bereaved has been widely documented. Although clinicians and recipients of these interventions advocate for their helpfulness in adapting to bereavement, research investigating the efficacy of visual art modalities has produced equivocal results and has not yet been synthesized to establish empirical support across settings. Accordingly, this review critically evaluates the existent literature on the effectiveness of visual art modalities with the bereaved and offers suggestions for future avenues of research. A total of 27 studies were included in the current review. Meta-analysis was not possible because of clinical heterogeneity and insufficient comparable data on outcome measures across studies. A narrative synthesis reports that therapeutic application of visual art modalities was associated with positive changes such as continuing bonds with the deceased and meaning making. Modest and conflicting preliminary evidence was found to support treatment effectiveness in alleviating negative grief symptoms such as general distress, functional impairment, and symptoms of depression and anxiety.
\end{abstract}

Keywords: grief, expressive arts, bereavement, therapy, efficacy

\section{Introduction}

Bereavement is a ubiquitous human experience that often recurs throughout a lifetime. ${ }^{1}$ Coping with the death of a loved one is often challenging and can affect bereaved individuals across multifaceted domains. Along with heightened emotions and longing for the deceased, bereaved individuals may experience symptoms of depression, anxiety, and cognitive disorganization. ${ }^{2}$ Those bereaved may also endorse physical manifestations of their distress, such as increased fatigue, greater propensity for developing illness, and overall poorer physical health outcomes than their non-bereaved counterparts. ${ }^{3,4}$ These symptoms are collectively identified as the negative symptoms of grief and can catalyze a myriad of functional complications, including decreased academic performance, ${ }^{5}$ job productivity, and quality of life. ${ }^{6}$

Early grief theories, such as those pioneered by Freud ${ }^{7}$ and Kubler-Ross, ${ }^{8}$ paralleled the universalistic aspect of bereavement by conceptualizing grief as a predictable process of identifiable stages. ${ }^{9}$ However, research has increasingly informed a paradigm shift toward a more nuanced understanding of loss. A large body of empirical evidence indicates multiple trajectories of grief rather than one standardized process, and leaders in the field suggest that reactions to loss can be as varied as the bereaved individuals 
themselves. ${ }^{10,11}$ Some people demonstrate considerable resilience when faced with loss, ${ }^{10}$ others experience significant but temporary impairment, and approximately $10-15 \%$ find themselves "stuck" in a persistent state of intense, complicated grief. ${ }^{12}$ Characteristics of the bereaved or of their loss can impact these grief trajectories. For example, relationship to the deceased and expectedness of the loss have been found to be particularly salient in influence on the intensity of grief reactions. ${ }^{12-14}$ As such, contemporary models of grief emphasize that the ways people adapt to loss vary as a function of individual differences.

Theorists and researchers currently embrace a range of empirically validated frameworks that account for the variegated trajectories of bereavement experiences, but two theories have emerged as the most demonstrable in empirical promise. First, the dual-process model of bereavement posits that grieving a loved one entails oscillating between orientation to the loss (i.e., continuing bonds with the deceased by expressing emotion related to the death and reconnecting with the memory of the loved one) and restoration of contact with a changed world (i.e., reengaging relationships and experimenting with new life roles). ${ }^{15}$ Second, the meaning reconstruction model of grief views grieving as a process of reaffirming or reforming a world of meaning that has been challenged by loss. ${ }^{16}$ In this constructivist-rooted perspective, people create and maintain a system of beliefs that permit them to anticipate and respond to their surroundings. Events' ascribed meaning must be either assimilated into the existing belief system or the system must be accommodated to make congruent meaning of the event. ${ }^{17}$ The death of a loved one is often a challenging event to make meaning of; as such, this model in summary characterizes grief as the process of reconstructing one's belief system and making meaning of one's loss. ${ }^{18}$ These two predominant bereavement theories are complementary. Both the dual-process model and the meaning reconstruction model view grief as a life-long process of renegotiating continuing bonds with the deceased and formulating meaning into life after the loss. ${ }^{19}$ The meaning reconstruction model proposes that the search for meaning is the bereaved individual's quest following loss, and the dualprocess model's cognitive oscillation of grief helps explain how the meaning is created. ${ }^{20}$

Research investigating the applicability of these models demonstrates signs of efficacy, particularly in regard to the ways in which continuing bonds with the deceased and meaning making are important mechanisms of successful adaptation to bereavement. Continuing bonds with the deceased facilitates grief resolution by helping the bereaved to preserve a sense of identity and meaningful connection with the past. ${ }^{21,22}$ When the bereaved are successful in finding meaning, evidence indicates that they fare better than their counterparts who struggle to make sense of the experience. Specifically, studies have reported that finding meaning is related to higher subjective well-being and more positive immune system functioning. ${ }^{23,24}$ Research provides empirical support for the processes proposed by the field's leading bereavement theories and suggests that bereaved people struggling to adjust to their loss could benefit from interventions driven around these two domains. As such, most empirically informed grief therapies aim to provide avenues for patients to explore continued bonds with the deceased, the personalized meaning behind their loss, and a reconstruction of purpose in life without their loved one. ${ }^{11}$

As bereavement theory evolved away from ubiquitous stage models toward more contextualized processing of varied individual loss, grief therapy similarly evolved in scope to include a range of treatment modalities. ${ }^{25}$ Many practices have made alterations to traditional grief psychotherapy to avoid a "one-size-fits-all" approach to treatment. ${ }^{26-28}$ An alteration frequently endorsed is the incorporation of expressive art modalities. Expressive art modalities are defined as the use of dance, drama, drawing, music, painting, photography, sculpture, and writing within the context of psychotherapy, counseling, rehabilitation, or medicine. ${ }^{29}$ Expressive art therapies are sometimes referred to as integrative or creative art therapies when purposively used in combination with treatment. ${ }^{30}$ Many manualized grief interventions incorporate expressive art techniques, such as Shear et al's ${ }^{31,32}$ treatment for complicated grief. Thompson and Neimeyer ${ }^{33}$ recently published a clinical manual with more than 50 suggested expressive art interventions to use with bereaved clients. The authors encouraged practicing grief therapists to use expressive art modalities to augment their existing clinical bereavement practice and incorporating expressive arts into grief therapy has been hailed as a way for clinicians to take their "game" to the next level. ${ }^{33,34}$

Not only has the incorporation of expressive arts with traditional grief therapy become increasingly documented but it is also common for those seeking grief therapy to receive care from a certified art therapist. More than $80 \%$ of trained art therapists report working with bereaved individuals. Further, bereavement/grief is self-reported as one of the top 10 specialties of practicing art therapists. ${ }^{35}$ In fact, peer-reviewed art therapy journals frequently publish educational editorial materials on grief theory in an effort to empirically inform art therapists' existing practice. ${ }^{19}$ Thus, bereaved individuals 
seeking therapeutic assistance for adjusting to their losses are likely to encounter exposure to expressive art modalities within a therapeutic context.

Theoretical support for the frequent combination of expressive arts and bereavement within a therapeutic setting can be found in the fields' overlapping treatment goals. Art therapists' orientation toward externalizing processes and facilitating insight meld naturally with meaning-focused therapeutic practice. ${ }^{25}$ The spontaneous creation of art, poetry, and performance offers a way to memorialize the relationship with the deceased and facilitate continuing bonds. ${ }^{36}$ Echoing the dual-process model's oscillating conceptualization of grief, theoretical models of art therapy posit that creativity is both a restorative and assertive act. ${ }^{37,38}$ Malchiodi ${ }^{40}$ noted that therapeutic art making served four purposes, which notably echo the assimilation and accommodation processes of the dual-process model: confronting mortality, meaning making, crisis resolution, and authentic emotional expression. Finally, both the leading theories of grief (i.e., the dual-process model and meaning reconstruction model) and of expressive arts (i.e., the expressive therapies continuum ${ }^{39}$ ) argue that creating meaning is the leading mechanism of change.

Although the expressive arts in general have been suggested by many clinicians as useful tools to facilitate adaptation to loss, use of the visual arts has particularly burgeoned within the field in recent years. Visual arts such as drawing, painting, photography, and multimodal forms have been commonplace in grief therapy ${ }^{33}$ Specifically, the creation of mandalas, scrapbooks, and thematic collages are among the most frequently implemented expressive art techniques with the bereaved. For example, photography, ie, the creation of a photographic narrative of the deceased loved one, is one of the core techniques in Shear et al's $\mathrm{s}^{32}$ manual for complicated grief. Visual arts' frequent use in the field is congruent with available historical context. Mourning and grief in funeral rituals often employ visual art to express loss, love, and remembrance across cultures. ${ }^{40,41}$ In addition, visual memorials are often created for remembrance, documentation, and healing for family and community of the decedent. ${ }^{42}$ Remarkably, despite the prevalence of implementing expressive art techniques with the bereaved, only recently studies have begun to investigate its efficacy or effectiveness. Given the frequent clinical application of visual art modalities for those bereaved, it is imperative that more investigative work be performed to evaluate this method of treatment, and a thorough review of the literature is warranted.

\section{Materials and methods Objectives of the empirical review}

This paper reviews and integrates the literature on the therapeutic application of visual art modalities with a bereaved population. Specifically, this review 1) evaluates empirical studies that report findings regarding the clinical effectiveness of visual art modalities as applied to the bereaved population; 2) identifies key mechanisms that may influence outcomes; 3) synthesizes the mechanisms identified across different functional outcomes; and 4) discusses weakness of the current state of the literature as well as promising avenues for future investigation. In addition, the paper discusses methodological considerations for future work examining whether visual arts are effective in promoting adaptation to bereavement when used in a therapeutic context.

\section{Definitions of terms}

This review utilizes the dual-process model of bereavement and the meaning reconstruction model to inform its evaluation of treatment effectiveness. This section provides and briefly describes the following terms used to categorize the review's scope and findings: 1) continuing bonds; 2) meaning making; 3 ) negative grief symptomatology; and 4) visual art modality.

\section{Continuing bonds}

"Continuing bonds" is a term that reflects the "ongoing attachment to the deceased." ${ }^{48}$ Continuing bonds with the deceased can be experienced emotionally, through missing, yearning, and feeling strongly connected to the loved one,$^{49}$ and cognitively, by thinking of and remembering the deceased person.$^{50}$ Continuing bonds can behaviorally entail talking to the loved one, maintaining his or her belongings post loss, feeling the presence of the loved one, and passing on the deceased's habits or virtues to others. ${ }^{51}$ Importantly, accepting the reality of the death and communicating the narrative of the loved one's life arc are also manifestations of adaptive continuing bonds with the decedent. 48 "Continuing bonds" is most often measured in quantitative bereavement research with the Continuing Bonds Scale (CBS) ${ }^{52}$ In qualitative research, "continuing bonds" is commonly measured by the presence and frequency of the endorsements of the aforementioned characteristics.

\section{Meaning making}

Meaning making, according to Thompson and Janigian, ${ }^{53}$ is the "ability to develop new goals and purpose, or to construct a sense of self that incorporates the significance of 
an experience." Drawing from this definition, researchers propose that meaning making following loss is a cyclical course in which the pain of bereavement (i.e., negative grief symptoms) prompts efforts to find meaning in the challenging event of the loss, with new meanings forming and integrating into a system of beliefs. ${ }^{18,54,55}$ In summary, meaning making during bereavement refers specifically to the reconciliation or reconfiguration of preexisting meanings with the death of a loved one. Meaning making can be manifested in the following documentable ways: sharing views that relate to the philosophical aspects of death and dying such as fairness, ${ }^{55}$ questioning, examining, and changing global meaning; ${ }^{56}$ discussing topics of religious connotations, ${ }^{55}$ expression of lessons learned, new insights gained, or changes in self or family since the death; ${ }^{55}$ and expression of strengthened familiar relations following the loss. ${ }^{57}$ Qualitative investigation of meaning making during bereavement often prompts participants to describe their loss experience in their own words and codes responses on the presence of the aforementioned documentable manifestations. For example, Lichtenthal et $\mathrm{al}^{58}$ assessed meaning-making processes in parents who had lost a child with open-ended written prompts (e.g., Have there been any ways in which you have been able to make sense of the loss of your child?). Similarly, Wheeler ${ }^{59}$ observed a "crisis in meaning" among bereaved parents in a qualitative study that revealed themes of parents' struggle to make sense of why the loss occurred, wondering what could have been performed to prevent the loss, preserving the significance of their child's life, and positive gains related to the loss. Quantitative measurement of meaning making during bereavement is most often assessed by directly asking participants to estimate how much they have been able to "make sense of" a loss on a Likert scale. ${ }^{60}$

\section{Negative grief symptoms}

Traditional grief theory suggested that bereavement was a one-dimensional experience of suffering, and research has historically focused on the negative outcomes following loss. However, our improved understanding reformulates bereavement as a complex system of experiences that can include positive changes, such as the aforementioned reconstruction of identity, meaning, and purpose. ${ }^{61}$ Thus, the negative aspects of bereavement are no longer considered to be the only formulation of grief, but are still viewed as integral and commonly endorsed components of bereavement. ${ }^{62}$ These negative grief reactions generally cause distress or impairment to the bereaved. The reactions may be exhibited affectively, emotionally, behaviorally, physiologically, cognitively, or socially. ${ }^{63}$ Negative grief symptoms are measured in the literature by endorsement of depressive symptoms, anxiety, poor social/relational functioning, cognitive disorganization, and physical health attributes. ${ }^{64}$ Quantitative measures of normative levels of negative grief symptoms are numerous, such as the Core Bereavement Items (CBI) and the Hogan Grief Reaction Checklist (HGRC). ${ }^{65,66}$ Quantitative measures of complicated grief symptoms include the Inventory of Complicated Grief (ICG) and the Texas Revised Inventory of Grief (TRIG). ${ }^{67,68}$ The aforementioned measures of negative grief symptoms have the strongest presence in bereavement literature, because they demonstrate strong psychometric properties across a number of bereaved populations.

\section{Visual art modality}

The scope of the review focuses on the effectiveness of visual art modalities within the context of bereavement therapy. Treatment parameters within the expressive arts are notoriously opaque. ${ }^{59}$ The American Art Therapy Association defines visual art as "drawing, painting, sculpture, and other art forms." ${ }^{69}$ For the purpose of this review, "other art forms" will echo previously published definition of visual art found in cross-disciplinary literature by including the following: printmaking, crafts (e.g., collage and scrapbooking), graffiti, photography, and ceramics. ${ }^{70}$ In an effort to replicate existing reviews of the expressive arts as treatment modalities, ${ }^{43-45}$ this review included studies that utilized visual art as both primary and adjunctive therapies.

\section{Methods}

\section{Search procedure and review parameters}

Pertinent peer-reviewed studies were identified through keyword searches in scientific databases that target the majority of published literature in the social and medical fields (e.g., PsycINFO, PubMed, Wiley Online Library, Web of Knowledge, and Google Scholar). Search terms (or word stems) consisted of ("art therap*" OR "arts psychotherap*" OR "expressive art*" OR "creative arts psychotherap*" OR "creative psycholog*" OR "visual art*") AND ("bereave*" OR "grief" OR "death"); where * denoted any wild card. After the initial search, specific examples of therapeutic visual art modalities (e.g., mandala and scrapbooking) were searched based on the previous findings to ensure comprehensiveness. Manual searches of prominent relevant journals (e.g., Death Studies, OMEGA, Art Therapy, and Arts in Psychotherapy) were also conducted. The reference sections of identified manuscripts were screened for additional studies. Finally, 
a separate search was conducted in thesis/dissertation databases using the same terms.

Studies in the current review satisfied the following inclusion criteria: 1) the study reported original research investigating psychosocial outcomes of therapeutic visual art modalities; 2) the intervention was specific to the modality of visual art (as opposed to music therapy, dance/movement therapy, play therapy, or drama therapy); 3) study participants had experienced bereavement-related loss; and 4) the study was in print or published in English.

The first author screened the abstracts of all identified articles for relevance to the current review, and full-text articles of pertinent studies were obtained. A total of 168 fulltext articles were obtained and screened by the first author, of which 141 were excluded for the following reasons: did not examine effectiveness of therapeutic visual art modalities $(\mathrm{n}=$ 131); participants had not experienced bereavement-related losses $(n=4)$ and were not in the context of interventions $(n=6)$.

\section{Results}

A total of 27 studies met all of the inclusion criteria. Table 1 provides details on the research design, sample composition and demographics, outcomes, and key findings of these studies. The subsequent sections first reviews the studies' research design characteristics. The following design components will be evaluated: study design, intervention characteristics (e.g., group vs. individual intervention, qualifications of individual administering intervention, and length of intervention), and outcome measurement. Subsequently, study results are summarized by the factors central to grief processing, as identified by Stroebe and Schut ${ }^{15}$ in the dual-process model of bereavement and by Neimeyer ${ }^{16}$ in the meaning reconstruction model: 1) continuing bonds, 2) meaning making, and 3) negative grief symptomatology. The empirical support for each domain is discussed.

\section{Study design}

Study samples were heterogeneous across studies. Fifteen (56\%) of the studies had a child/adolescent sample, 10 (37\%) had an adult sample, and two (7\%) had a combined sample with a focus on family systems. Ages ranged from 18 to 94 years in the adult samples and 5 to 17 years in the child/ adolescent samples. Average total number of participants was 26 ( $\mathrm{SD}=24.3)$. The majority of studies were correlational with no control group (93\%). Of the experimental designs, one study used a waitlist control group ${ }^{71}$ and one used a treatment as usual control. ${ }^{72}$ Approximately $19 \%$ of studies were cross-sectional, while $81 \%$ were longitudinal; $33 \%$ of studies included a follow-up session. The majority of studies were qualitative in nature $(62 \%)$, while $19 \%$ were mixed methods and $19 \%$ were quantitative.

\section{Intervention characteristics}

Most of the included studies used a group intervention (63\%), although individual (30\%) and family (7\%) approaches were also represented. The interventions included psychotherapy and counseling with adjunct visual art modalities (33\%), art therapy support groups (33\%), individual art therapy interventions $(26 \%)$, and interventions using both individual and group formats $(8 \%)$. The interventions were conducted by certified art therapists (7\%), licensed counselors or psychologists $(26 \%)$, art therapy doctorate students (26\%) clinical psychology doctorate students $(30 \%)$, and co-facilitators of licensed clinicians and certified art therapists (11\%). Interventions spanned an average of 9 weeks for an average number of 83-minute sessions, totaling an average of 6.7 intervention hours per participant. Other characteristics of the samples and the studies are presented in Table 2. These variables were usually coded on the basis of the mean, but the medians or midpoints of the ranges were used when authors failed to report this information.

\section{Outcome measurement}

Outcome measurement varied widely across studies despite similarities in treatment outcome foci. There was insufficient statistical information to obtain a pooled estimate of treatment effect; thus, creating a meta-analysis of the incorporated studies was beyond the remit for the current investigation. Outcomes were assessed using three different reporting methods: participants' self-report, reports of significant others, and clinician-rated judgment. Instruments that required the participants to respond to questions about themselves on a conventional rating scale or open-ended were considered self-report. Rating scales that involved the evaluation of outward behaviors by other reporters were grouped as other report. Finally, there were instances in which outcomes were determined by a trained professional's assessment of the participants' functioning that was usually based on an accepted standard of distress (e.g., severity of depressive symptoms) or the participants' artwork created during the intervention (e.g., Kinetic Family Drawing [KFD]). Approximately 56\% of studies used participants' self-report, 11\% included reports of significant others, and $89 \%$ used various formats of clinicianrated judgment as a form of outcome measurement. Approximately $26 \%$ of studies used only clinician-rated judgments 


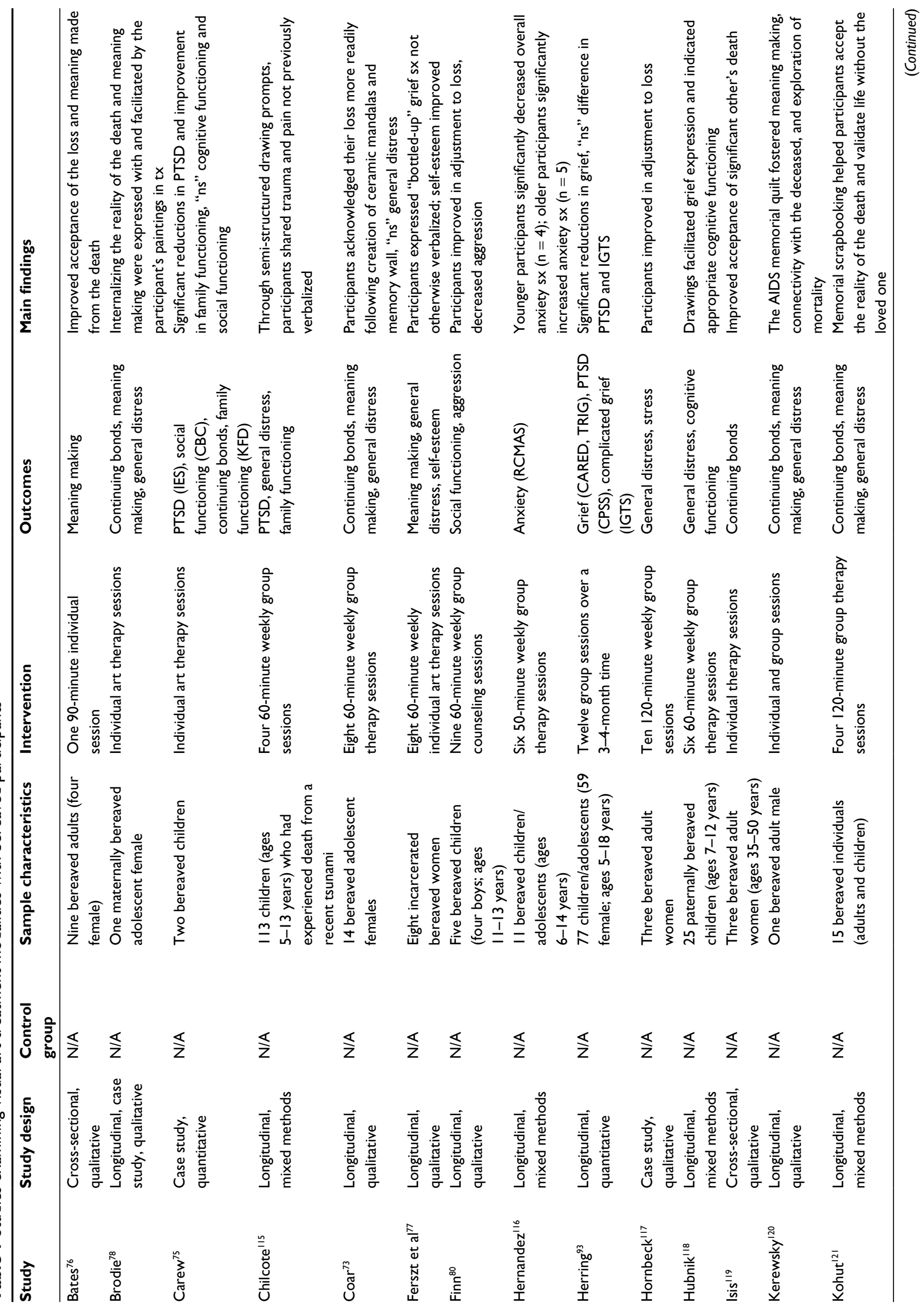




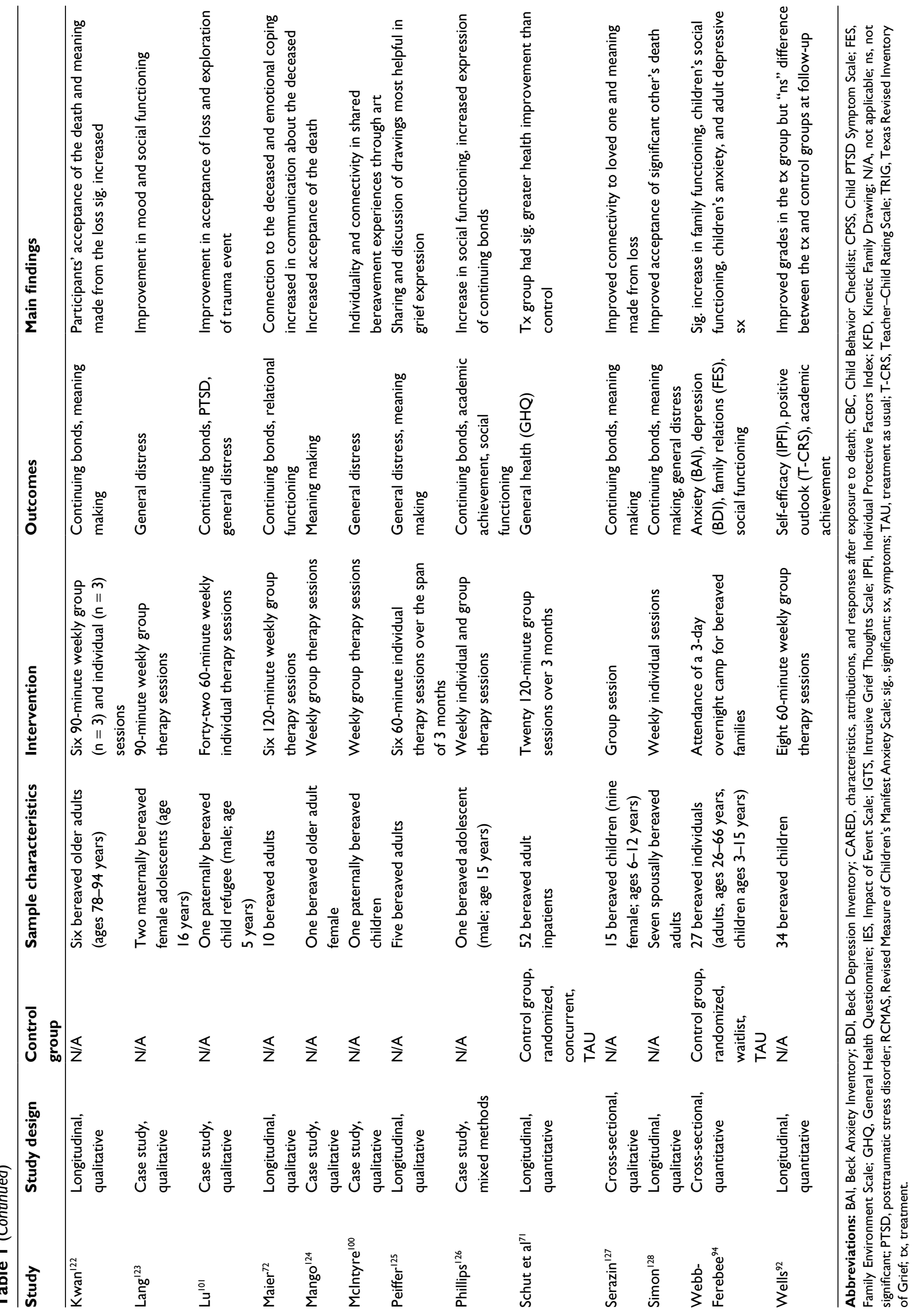


Table 2 Study characteristics

\begin{tabular}{lllll}
\hline Study characteristics & $\begin{array}{l}\text { No of } \\
\text { studies }\end{array}$ & Mean & SD & Range \\
\hline Year of study report & 27 & $200 \mathrm{I}$ & - & $198 \mathrm{I}-2013$ \\
Total participants & 26 & 14.3 & - & $\mathrm{I}-1 \mathrm{I3}$ \\
Length of sessions (minutes) & 17 & 83 & 27.6 & $60-120$ \\
Weeks of intervention & 17 & 9.1 & 9.6 & $\mathrm{I}-42$ \\
\hline
\end{tabular}

as reporting methods. Overall, researchers used the three reporting methods to assess outcomes in eight domains: general distress (48\%), continuing bonds (44\%), meaning making (41\%), relational functioning/social adjustment (11\%), trauma symptoms ( $9 \%)$, cognitive functioning $(6 \%)$, anxiety (6\%), and depression (3\%). Research outcomes of the continuing bonds and meaning making domains are reviewed in more detail in the following sections. The domains of general distress, trauma symptoms, relational functioning/social adjustment, cognitive functioning, anxiety, and depression are subsequently reviewed within the combined context of negative grief symptoms. Some qualitative studies indicated an outcome focus of "grief" or "healing from the loss" but did not delineate specific characteristics of these treatment aims. Upon further review of these studies, it became evident that investigators were looking for signs of general distress secondary to the participants' bereavement. Thus, these outcome domains were categorized as general distress and were included in the review of negative grief symptomatology. The following sections present a summary of results categorized by the three outcome domains of: 1) continuing bonds, 2) meaning making, and 3) negative grief symptoms. The empirical support for each domain is discussed.

\section{Continuing bonds}

A total of 12 (44\%) studies examined continuing bonds as an outcome measure of treatment effectiveness. The majority of studies investigating continuing bonds were qualitative. The aggregate of these findings suggests that visual art modalities facilitated participants' adaptive preservation of ties with the deceased, and investigators usually argued this finding as an indicator of the treatment thereby aiding the healing process of grief. One important theme that arose across these qualitative studies was acceptance of the death. Maier $^{72}$ found that participants who created a scrapbook memorializing their deceased loved ones in a grief support group reported that the scrapbooks helped them with "radical acceptance" of the loss as the creation process helped them "witness the reality" of the decedent's life arc. Coar ${ }^{73}$ found that participants that completed eight 60-minute weekly group therapy sessions incorporating the creation of ceramic mandalas facilitated participants' adaptation to their loss and cultivated continued ties with the deceased. One study stood out by its singularity in measuring continuing bonds with projective measurement of participant artwork created during the intervention. Carew evaluated continuing bonds in his sample of parentally bereaved children with the KFD test,${ }^{74}$ in which participants are asked to draw a picture of their families. ${ }^{75}$ Carew found that his participants' family drawings incorporated the deceased caregivers more integrally following their individual art therapy sessions than their pre-intervention KFDs, and interpreted this finding as indication of improved continuing bonds with the decedent. ${ }^{74}$ Another theme that arose within the domain of continuing bonds was maintaining adaptive attachment to the decedent while coming to terms with the loss, a hallmark of the dualprocess model's oscillating process of grief. For example, narrative theme evaluations conducted by Bates ${ }^{76}$ of her bereaved participants revealed endorsement of fondness and storytelling about the deceased that entailed the full life arc of their life story, demonstrating persevering attachment with healthy acknowledgment of the death.

\section{Meaning making}

A total of $11(41 \%)$ studies examined meaning making as an outcome measure of treatment effectiveness. Interestingly, no included study evaluated this marker of bereavement adaptation quantitatively, despite available measures. Instead, studies focused on qualitative self-report, often by participants' evaluation of treatment at follow-up, and clinician-rated judgment. In a study of eight bereaved incarcerated women who completed 60-minute weekly individual therapy sessions, all participants expressed increased understanding of the events surrounding their loss and the ways in which it impacted their emotional health and self-esteem. ${ }^{77}$ Clinician-rated judgment was frequently made from inferences about participants' visual art output. For example, Brodie ${ }^{78}$ reported evidence of her case study's meaning-making processing through painting modalities by her use of the figure emerging from the ground, a motif originally connected to meaning exploration by Simon. ${ }^{79}$ Finn ${ }^{80}$ reported that incorporating visual art techniques in her group counseling program for bereaved youth helped her clients adjust to their loss and learn new coping skills based on participants' written evaluation of the group. Finn $^{80}$ gathered quantitative data on participants' rating of how well they met five distinct therapeutic goals on a 4-point scale where higher scores indicated greater achievement of the objective, and reported that participants rated each item 
with a 3 or 4 (indicating strong endorsement of the objectives) but failed to provide mean and SD of the scores.

\section{Negative grief symptoms}

A total of 15 (56\%) studies examined grief symptomatology as an outcome measure of treatment effectiveness. In the general bereavement literature, assessment of negative grief symptomatology can encompass a myriad of outcomes such as various functional impairments, physical health symptoms, emotional well-being, and psychological concerns. This review's included studies used the following specific domains to investigate the overall outcome of negative grief symptomatology: general distress, depression, anxiety, cognitive functioning, relational functioning/social adjustment (i.e., social functioning, family functioning, relational functioning, and self-esteem), trauma symptoms, general physical health, academic achievement, aggression, and complicated grief symptoms. This outcome domain entailed the majority of quantitative measures used by the reviewed literature. The included studies quantitatively evaluated the following components of negative grief outcomes: symptoms of anxiety with the Beck Anxiety Inventory (BAI) ${ }^{81}$ and the Revised Measure of Children's Manifest Anxiety Scale (RCMAS); ${ }^{82}$ depressive symptoms with the Beck Depression Inventory II (BDI-II) ${ }^{83}$ social/familiar functioning with Family Environment Scale (FES) ${ }^{84}$ social functioning with the Child Behavior Checklist $(\mathrm{CBC})^{85}$ and the Teacher-Child Rating Scale (T-CRS); ${ }^{86}$ resiliency with the Individual Protective Factors Index (IPFI) ${ }^{87}$ symptoms of posttraumatic stress disorder (PTSD) with the Child PTSD Symptom Scale (CPSS) ${ }^{88}$ and Impact of Event Scale (IES); ${ }^{89}$ complicated grief symptoms with the Intrusive Grief Thoughts Scale (IGTS) ${ }^{90}$ and the TRIG; ${ }^{68}$ and physical health with the General Health Questionnaire (GHQ). ${ }^{91}$ In addition, Wells ${ }^{92}$ recorded grade marks of pediatric participants as a quantitative measure of academic achievement.

Reviewing these results cumulatively, there is modest but conflicting evidence for visual arts' effectiveness in addressing these syndromes. Schut et $\mathrm{al}^{71}$ found that both the treatment group receiving weekly group art therapy sessions and the waitlist control group demonstrated general health improvement over the course of the study, but that the treatment group receiving weekly art therapy sessions improved significantly more than the control group. Wells ${ }^{92}$ found that in a sample of bereaved children $(n=34)$ receiving weekly art therapy sessions found a slight overall improvement in the measured outcomes of academic achievement, self-efficacy, and positive outlook, but there was no statistically significant difference between the treatment and control group at followup in these domains. Similarly, after traumatically bereaved children completed 12 therapeutic sessions with adjunct visual art modalities, Herring ${ }^{93}$ reported results that evidenced significant reductions in cognitive and affective grief reactions and avoidance symptoms similar to those found in randomized controlled trials of grief-focused interventions, as measured by the CPSS and the IGTS. However, reductions in reexperiencing and arousal symptoms were not found. In fact, arousal symptoms appeared to increase throughout treatment for a subgroup of children who reported high levels of anger and fighting by current caregivers. ${ }^{93}$ Webb-Ferebee ${ }^{94}$ found that younger participants significantly decreased overall anxiety symptoms, while older participants significantly increased anxiety symptoms, as measured by the RCMAS.

\section{Visual art modality}

The visual art modalities administered by included studies were heterogeneous. Thirteen (48\%) studies evaluated interventions that administered multiple modes of therapeutic visual art techniques. For example, one study evaluated grief outcomes following participants' completion of photographic essays and process-oriented assemblages about their loved one. ${ }^{76}$ Another study asked participants to draw an abstract picture depicting the feelings of their grief, create a memory box, and draw a metaphorical bridge of the progress of their grief, among other activities. ${ }^{117}$ Nine (33\%) studies implemented therapeutic drawing or painting exercises. Specific examples of drawing or painting examples include a family portrait drawing and drawing the feelings of their grief. ${ }^{92}$ Two studies $(7 \%)^{72,121}$ examined impact of a scrapbooking bereavement group in which bereaved individuals created a scrapbook about their loved one. One study evaluated participants who created ceramic mandala tiles to create a mosaic reflection. ${ }^{73}$ Another study assessed making a memorial quilt. ${ }^{120}$ Finally, one study investigated the use of Chinese brush strokes in bereavement-related tasks. ${ }^{122}$

\section{Discussion}

The purpose of this review was to evaluate the extant literature regarding visual art therapy techniques with a bereaved clinical population. The number of studies that were relevant to this particular review was limited $(n=27)$, qualifying the strength of conclusions drawn from key results. Further, the heterogeneity of the reviewed studies offers weak external validity and limits their findings' generalizability to other settings or populations. The variations in the model and content of visual art modalities also lend complication in determining 
efficacy and replicability. Nevertheless, a number of interesting trends emerged that provide avenues for future research considerations.

When reviewed cumulatively, the included experimental studies documented modest improvements in the facilitation of continuing bonds and meaning making with participants who experienced visual art treatment modalities compared with participants assigned to a control group or who underwent alternative treatments. Nonexperimental studies also provided support for visual art modalities as an effective tool to facilitate continuing bonds and meaning making, although the majority of these findings were qualitative and based on subjective self-report or clinician-rated judgments. There is weaker support for this treatment modality's efficacy in alleviating negative grief symptoms, as was exemplified by both qualitative and quantitative investigation. Indeed, some studies reported conflicting results within their own participants, as some improved in negative grief symptoms over the course of treatment while others showed no significant improvement or even worsened. This finding provides support for the distinction between these constructs and the movement for conceptualizing grief as a multidimensional experience. Our findings indicate that therapeutic use of visual art modalities with bereaved populations may aid the methods for acquiring positive skills in adapting to bereavement (i.e., sense making, benefit finding, and preservation of the loved one's legacy) but there is less evidence to support its effectiveness in alleviating the pain of loss. This result is congruent with the existing literature on the investigated domains of grief. For example, meaning making and post-loss have been found to predict the positive outcomes for bereaved individuals across numerous studies. ${ }^{95}$ It is also notable that meaning making is a difficult process for the bereaved and is rarely successful even in those who intentionally search for meaning following a loss, ${ }^{96}$ which lends particular significance to the documented facilitation of meaning made in bereaved participants.

The minimal impact on negative grief symptoms may also be congruent with recent literature. The degree to which any intervention significantly alleviates negative symptoms within the range of normative grief reactions (as opposed to complicated grief) has been contended in the literature. ${ }^{97,98}$ A meta-analysis of bereavement interventions suggested that treatment recipients with indications of complicated grief experience the greatest benefit and alleviation of functional impairment. ${ }^{11}$ Further, negative grief symptoms may not be the most reliable marker of "progress" following the death of a loved one. A prospective study conducted by Bonanno et $\mathrm{al}^{99}$ found strong evidence against the idea that those who do not exhibit grief following a loss are insecurely attached and emotionally distant. Thus, the absence of negative grief symptoms is not necessarily a marker of successful or unsuccessful adaptation to the death, especially considering that courses of grief responses are variegated, with some individuals endorsing delayed or inhibited grief. ${ }^{10}$ There is also substantial evidence that negative grief symptoms alleviate over time for the majority of those bereaved, even without the assistance of therapeutic intervention. ${ }^{99}$ Thus, much of bereavement therapy aims to facilitate the strength-based approaches to grief, focusing on positive outcomes and cognitive understanding of the impacts of the loss. ${ }^{96}$ Thus, grief therapy is sometimes considered a preventative approach to bereavement, to buffer possible manifestations of impaired functioning, rather than the traditional aims of psychotherapy for direct alleviation of targeted symptoms. ${ }^{11}$ As such, this review's finding that visual art modalities demonstrate some evidence of developing positive outcomes but not impacting negative outcomes may indicate congruent trends with existing treatment aims for the bereaved.

Perhaps the most convincing piece of evidence in support of continued research can be found in the self-report measures collected by investigators. Participants overwhelmingly endorsed a positive subjective impact of the treatments incorporating visual art modalities. Across several studies, participants rated their well-being as significantly improved. ${ }^{100,101}$ Although this finding is ineffectually captured with measurement of objective changes, it warrants further attention and perhaps speaks to the efficacy of visual art techniques witnessed by clinicians across disciplines. The use of positive or growth-oriented measures (e.g., personal growth, posttraumatic growth, benefit-finding, and self-efficacy) could be an avenue of future research that provides insight into participants' experiences and whether they translate to objective outcomes.

\section{Limitations and considerations for future research}

The findings of this review highlight significant problems in number, content, and rigor of the relevant existing literature. Our review uncovered substantial weaknesses in the following domains: 1) operationalized definitions, 2) study design, 3) outcome measurement, 4) underreporting of individual difference variables, and 5) underreporting of intervention characteristics and development. Each domain is examined in more detail in the following sections followed by considerations for addressing each domain. 


\section{Operationalized definitions}

A reappearing difficulty in compiling the current literature review was the paucity of operational definitions, particularly within the niche of visual art interventions. Where does one differentiate between visual art therapy techniques, art as therapy, expressive art modalities, and creative expressionism within psychotherapy? As previously noted, this review could not rely on an existing operational definition of therapeutic visual art modalities. Rather, the inclusion criteria for types of interventions reviewed were created with reference to multidisciplinary sources. ${ }^{69,70}$ Expressive art therapy has historical difficulty in forming an accurate, comprehensive, and concise definition of its services (a thorough historical review is given in the study by Kalmanowitz and Potash ${ }^{102}$ ). The American Art Therapy Association's current definition of its treatment parameters has been contradictorily criticized for both its detail and incompleteness: (art therapy is)

art media, the creative process, and the resulting artwork to explore their feelings, reconcile emotional conflicts, foster self-awareness, manage behavior and addictions, develop social skills, improve reality orientation, reduce anxiety, and increase self-esteem. ${ }^{69}$

This definition is difficult to truncate, and researchers have recommended for American Art Therapy Association to seek a simpler definition that more clearly conveys the scope of the profession. ${ }^{104,105}$ Spooner ${ }^{105}$ describes the expressive arts' lack of operational definitions as a marketing problem: because practitioners using these methods are unable to clearly articulate their scope of practice to other disciplines, art therapy is suffering from a lack of brand awareness. The confusion over treatment characteristics and categorization is negatively affecting researcher's ability to conduct research with reliable terminology. This is especially true when disciplines outside of art therapy attempt to evaluate efficacy of modalities within the scope of their practice, as is the case in the current review. Used consistently, clear and memorable definitions would enhance the empirical study of expressive arts in therapy. Specifically, clarifying treatment terminology and defining brackets of intervention would facilitate crossdisciplinary research methods investigating the expressive arts as therapeutic modalities.

\section{Study design}

The review of included studies' methodologies points to the importance of rigorous study design. Only $7 \%$ of included studies used a control group. Researchers have highlighted the importance of using control groups in research with bereaved. ${ }^{106}$ For intervention efficacy studies, particularly with the bereaved, it is evident that an active control group is essential to help establish causation and strengthen internal validity. Without control groups, it is difficult to examine whether the suggested facilitation of meaning making and continuing bonds could be attributable to the visual art intervention or whether these effects occurred due to other factors. When using control groups, other important aspects of study design with bereaved populations are the use of random or matched assignment, inclusion of enough participants for sufficient power due to high rates of attrition, and preventing poor adherence to the intervention. ${ }^{99}$ Bereavement researchers have advocated for evaluation of grief therapies to be conducted in a laboratory setting or in an online format for increased validity and reliability and decreased attrition to reach necessary statistical power. ${ }^{107}$ This would improve intervention efficacy, which can later be generalized as appropriate, but is difficult in application for clinicians conducting research alongside their existing clinical practice.

Practicing clinicians who use expressive art modalities with grieving individuals are often confident of the therapeutic benefits, but can rarely explain with precision how the artwork was produced in therapy or what specific factors contributed to client improvement. ${ }^{108}$ Furthermore, many clinicians often express doubt in the feasibility of communicating therapeutic benefits of the expressive arts through research. Consequently, quantitative analysis of visual art effectiveness is scant, and qualitative analysis is varied in form and rigor. The findings of this review reveal a heavy reliance of the case study approach in research conducted by both psychologists and art therapists. The case study avenue of research provides helpful qualitative detail on individual treatment levels, but leaves a paucity of generalizable quantitative data or other evidence for larger-scale effectiveness. The frequent implementation of single case design may reflect the regularity of visual arts' use within the clinical field. Indeed, one significant finding from this review was the prevalence of practicing clinicians' as the primary research investigators. However, if the majority of the literature on the use of visual arts with grief therapy is conducted by practicing clinicians as this review suggests, the field's aim of more robust research methodology faces some barriers. For example, the majority of clinicians do not work in settings conditional for experimental research. Community mental health clinics, private practice, and small nonprofit organizations rarely have formal structures or financial support for complex study design, requiring clinicians in these settings 
to navigate research endeavors on their own. Art therapists may face particular challenges in conducting independently driven, robust methodologies as research is often only peripherally incorporated into art therapy education programs. Art therapists report feeling far more confident about their clinical skills than research skills, and offer skepticism in their ability to provide evidence for their practices' efficacy. ${ }^{105}$ This mindset is demonstrable by art therapists' reported distaste for the spreading "clinification syndrome" of art therapy, ${ }^{105}$ a term used to describe the perception of increased favoritism of empirically driven treatment approaches at the detriment of art therapists' uniquely layered artistic expertise.

Accordingly, one future avenue of research that is sensitive to the needs of practicing clinicians aiming to evaluate their practice is the implementation of baseline symptom measurement. Pre-post outcomes provide empirical support and can elevate the rigor of clinical evaluation to a single-case experimental study. Using brief quantitative measures in this regard could also benefit the clinician's therapeutic practice as results offer feedback and potential courses of discussion within the treatment setting. Specific examples of possible quantitative measures are offered in the following section.

\section{Outcome measurement}

The majority of quantitative outcome measures used in the included studies were well validated and reliable measurement tools. Collectively, these measures allowed assessment of a wide scope of negative grief symptoms, but were limited in their ability to quantitatively capture treatment effects on continuing bonds and meaning making. Most studies additionally included an essay evaluation form, which typically used single items to assess the participants' subjective experiences during and after the intervention. Other measures developed by the researchers were based on several single-item Likert-scale questions and were sometimes used as supplemental measurement tools, but investigators puzzlingly did not report the mean or SD of these outcomes. Nonetheless, the inclusion of a variety of assessments helped provide triangulation of data and is a methodological strength.

A noted trend in the outcome measurement of the included studies of this review is the propensity to rely on participants' artwork created during grief treatment as an indicator of outcome change. For example, $\mathrm{Carew}^{75}$ used the KFD style to measure family environment and relational functioning. Many studies that included this form of clinician-rated judgment outcome measurement were not mixed methods, and this pattern compromises their internal validity. Luckily, increased recognition of theory-driven data has yielded a number of empirically validated measures of bereavement adaptation. The CBS is a brief measure that rates 10 dimensions of continuing bonds (e.g., reminiscing, linking objects, and ongoing expressions of love). ${ }^{52}$ Meaningmaking processes can be reliably assessed with prompts for participants to consider whether they have been able to make sense of their loss and in what ways. ${ }^{58}$ For a singular but comprehensive measure of grief symptomatology, the HGRC provides a multidimensional report on both negative and positive aspects of bereavement experiences, such as personal growth, anger, and cognitive disorganization. ${ }^{66}$ Since the HGRC's development, it has been identified as one of the most widely employed instruments for measuring grief reactions and personal growth after a loss. ${ }^{109}$ In addition, the HGRC has been found to be compatible with the meaning reconstruction model of grief, allowing for consistency in grief conceptualization, symptom tracking, and treatment aims. ${ }^{17}$ This section only listed a limited number of measures and focused on the outcomes investigated for the purpose of this review (i.e., continuing bonds, meaning making, and negative grief symptomatology), where a more comprehensive review of available bereavement measurements is given in the studies by Minton and Barron ${ }^{110}$ and Neimeyer. ${ }^{111}$

Outcome measurement used in the included studies of this review provides modest preliminary support for visual art treatment modalities' effectiveness in facilitating continuing bonds and meaning making, largely based on subjective outcome measures of participant self-report and investigators' clinical judgment. In addition to objective outcome measures of continuing bonds and meaning making, future research may benefit from assessment of other positive changes that can occur during bereavement such as posttraumatic growth and positive identity changes. These outcomes can be reliably assessed through well-established measures such as the Personal Growth subscale of the HGRC and the Grief and Meaning Reconstruction Inventory. ${ }^{66,112}$ Use of these measures in future research endeavors will address the paucity of objective outcome measurement in the literature while also capturing possible intervention effects that would have otherwise been missed. When used in conjunction with clinician-rated judgment of symptom improvement and projective tests of visual artwork created during the course of the intervention, these tools can facilitate validation and clarification of the mechanisms of change within existing clinical practice. 


\section{Underreporting of individual difference variables}

Given the complexity of individual difference variables' influence on adjustment to bereavement, it is especially important to report participant demographics and characteristics of the loss experience when evaluating the effectiveness of grief therapies. However, few of the reviewed studies reported participants' type of loss (i.e., homicide, suicide, illness, or accident), expectedness of the loss, relationship to the deceased, or other important variables that influence the trajectories of grief expressionism. Future intervention research should not only gather this information for inclusion of publications but also allow it to inform clinician decision-making of intervention characteristics. Current bereavement theory emphasizes the variety within reactions to bereavement, despite its ubiquitous nature, and is beginning to inform the development of applicable interventions based on participant characteristics. This is evidenced by Thompson and Neimeyer's ${ }^{33}$ recently published manual of more than 50 expressive art techniques to incorporate into grief therapy, many of which are introduced by guiding the reader in situational characteristics of the client or the death experience that would yield most efficacious results.

If research further substantiates the benefit of therapeutic visual art modalities with the bereaved, empirical focus should shift to investigation of possible mechanisms of change. This next step would be advanced by identifying treatment components most salient to influencing measurable outcomes. For example, in the included studies of this review, visual art modalities were often an adjunct to other formulation of grief therapy. Parceling psychoeducation about grief, exposure to grief cues, encouragement of emotional expression, cognitive or meaning-oriented interventions, and group format vs. individual disclosure would allow for an elevated understanding of the underlying influencers of objective outcomes in this modality of grief therapy. Investigating these characteristics may enhance bereavement interventions by providing guidance on the ways individual difference variables influence the efficacy of particular treatment methods.

\section{Underreporting of intervention characteristics and development}

A rarer but equally problematic limitation of included studies was the exclusion of specific treatment descriptions. Every included study identified the visual art modality used within the treatment setting (e.g., drawing about the loss and making a memorial scrapbook) but few specified treatment detail over time. This is especially problematic to the literature's treatment reliability as only $9 \%$ of included studies reported following a treatment manual. Similarly, few studies explained the theoretical underpinnings and the operational implementation of their interventions. It was rare for studies to describe how the interventions were developed, which empirically informed theories were drawn from, or proposed hypotheses for agents of change. This reference deficit to theoretical frameworks has been similarly implicated in literature reviews of bereavement therapies unrelated to expressive arts. ${ }^{11}$ Future research endeavors aiming to investigate treatment efficacy would enhance their methodology and appropriateness if informed by specific treatment aims rooted in existing grief theory. Furthermore, as in most intervention research, investigators in the reviewed studies failed to qualify their findings with clarification over which clients were treated by the same therapist. This absence can pose validity issues, as researchers have noted that such nesting can lead to the overestimation of treatment benefit because of therapist effects or group effects. ${ }^{13,114}$

\section{Conclusion}

This review examined the clinical effectiveness of using visual art modalities in a therapeutic context with bereaved individuals. The applicability of the Stroebe and Schut's dual-process model of bereavement and Neimeyer's meaning reconstruction model for understanding treatment outcomes and conceptualizing future avenues of research was also investigated. The heterogeneity of the studies investigated by this review indicates that visual art modalities are a psychotherapeutic approach adaptive to an assortment of clinical situations. Although this review revealed modest but promising preliminary evidence of visual art modalities' effectiveness with a bereaved population, the existing literature is scant, heterogeneous, and thereby difficult to generalize. Important work in the area of using visual art modalities with grief therapy has been completed, but the designs of the majority of the available studies do not provide sufficient evaluation of this treatment modality and a great deal of work remains. Findings from our review suggest that grief interventions using visual art techniques facilitate continuing bonds and meaning making, but there is little evidence to support a significant impact on negative grief symptomatology. Furthermore, we know very little of the processes by which visual arts facilitate continuing bonds and meaning making. Given the multitude of individual differences and responses to loss, future research into the increasingly varied methods of grief therapies used to address the diversity of the bereavement experience is warranted. In the next stage of research examining expressive art as treatment 
modalities with the bereaved, an increase in theory-driven interventions, experimental research designs, assessment of individual difference variables, and quantitative analysis should be prioritized. As described earlier, operational definitions, experimental research designs, inclusion of individual difference variables, and empirically validated assessments are promising avenues that can guide future considerations within this area.

\section{Disclosure}

The authors report no conflicts of interest in this work.

\section{References}

1. Hagman G. Beyond decathexis: toward a new psychoanalytic understanding and treatment of mourning. In: Neimeyer RA, editor. Meaning Reconstruction and the Experience of Loss. Washington, DC: American Psychological Association; 2001:13-31.

2. Utz RL, Carr D, Nesse R, Wortman CB. The effect of widowhood on older adults' social participation: an evaluation of activity, disengagement, and continuity theories. Gerontologist. 2002;42(4):522-533.

3. Prigerson HO, Jacobs SC. Traumatic grief as a distinct disorder: a rationale, consensus criteria, and a preliminary empirical test. In: Henk $\mathrm{S}$, editor. Handbook of Bereavement Research: Consequences, Coping, and Care. Washington, DC: American Psychological Association; 2001:613-645.

4. Murphy SA, Johnson LC, Weber NA. Coping strategies following a child's violent death: how parents differ in their responses. OMEGA. 2002;45(2):99-118.

5. Servaty-Seib HL, Hamilton LA. Educational performance and persistence of bereaved college students. J Coll Stud Dev. 2006;47(2):225-234.

6. Neimeyer RA, Laurie A, Mehta T, Hardison H, Currier JM. Lessons of loss: meaning-making in bereaved college students. New Dir Stud Serv. 2008;(121):27-39.

7. Freud S. Mourning and melancholia. Psychoanal Rev. 1924;11:77.

8. Kubler-Ross E. On Death and Dying. New York: Taylor \& Francis; 1969.

9. Archer J. Theories of Grief: Past, Present, and Future Perspectives. Washington, DC: American Psychological Association; 2008.

10. Bonanno GA. Loss, trauma, and human resilience: have we underestimated the human capacity to thrive after extremely aversive events? Am Psychol. 2004;59(1):20-28.

11. Currier JM, Neimeyer RA, Berman JS. The effectiveness of psychotherapeutic interventions for bereaved persons: a comprehensive quantitative review. Psychol Bull. 2008;134(5):648.

12. Prigerson HG, Horowitz MJ, Jacobs SC, et al. Prolonged grief disorder: psychometric validation of criteria proposed for DSM-V and ICD-11. PLoS Med. 2009;6(8):e1000121.

13. Holland JM, Neimeyer RA. Separation and traumatic distress in prolonged grief: the role of cause of death and relationship to the deceased. J Psychopathol Behav Assess. 2011;33(2):254-263.

14. Currier JM, Holland JM, Neimeyer RA. Sense-making, grief, and the experience of violent loss: toward a mediational model. Death Stud. 2006;30(5):403-428.

15. Stroebe MS, Schut H. The dual process model of coping with bereavement: rationale and description. Death Stud. 1999;23(3):197-224.

16. Neimeyer RA. Meaning Reconstruction \& the Experience of Loss. Washington, DC: American Psychological Association; 2001.

17. Neimeyer RA, Sands DC. Meaning reconstruction in bereavement: From principles to practice. In: Neimeyer RA, Harris DL, Winokuer HR, Thornton GF, eds. Grief and bereavement in contemporary society: Bridging research and practice. New York: Routledge; 2011;9-22.
18. Gillies J, Neimeyer RA. Loss, grief, and the search for significance: toward a model of meaning reconstruction in bereavement. J Constructivist Psychol. 2006;19(1):31-65.

19. Lister S, Pushkar D, Connolly K. Current bereavement theory: implications for art therapy practice. Art Ther. 2008;35(4):245-250.

20. Stroebe MS, Schut H. Models of coping with bereavement: a review. In: Henk S, editor. Handbook of Bereavement Research: Consequences, Coping, and Care. Washington, DC: American Psychological Association; 2001:375-403.

21. Bowlby J. Loss: Sadness and Depression. Vol. 3. New York: Basic Books; 1980.

22. Field NP. Whether to relinquish or maintain a bond with the deceased. In: Stroebe MS, Hansson RO, Schut H, et al., editors. Handbook of Bereavement Research and Practice: Advances in Theory and Intervention. Washington, DC: American Psychological Association; 2008:113-132.

23. Uren TH, Wastell CA. Attachment and meaning-making in perinatal bereavement. Death Stud. 2002;26(4):279-308.

24. Bower JE, Kemeny ME, Taylor SE, Fahey JL. Finding positive meaning and its association with natural killer cell cytotoxicity among participants in a bereavement-related disclosure intervention. Ann Behav Med. 2003;25(2):146-155.

25. Neimeyer RA. Techniques of Grief Therapy: Creative Practices for Counseling the Bereaved. Abingdon: Routledge; 2012.

26. Thompson BE, Berger JS. Grief and expressive arts therapy. In: Thompson BE, Berger JS, editors. Grief and Bereavement in Contemporary Society: Bridging Research and Practice. New York: Routledge; 2011;303-313.

27. Mancini AD, Bonanno GA. Resilience in the face of potential trauma: clinical practices and illustrations. J Clin Psychol. 2006;62(8):971-986.

28. Miles-Mason ES. A case study illustration of grief therapy using culturally-sensitive, integrative techniques. Grad Stud J Psychol. 2005;7:37-45.

29. Malchiodi CA. Creative interventions and childhood trauma. In: Malchiodi CA, editor. Creative Interventions with Traumatized Children. New York: Guilford Press; 2008:3-21.

30. Estrella K. Expressive therapy: an integrated arts approach. Express Ther. New York: The Guilford Press; 2005:183-209.

31. Shear MK, Frank E, Foa E, et al. Traumatic grief treatment: a pilot study. JAMA Psychiatry. 2001;158(9):1506-1508.

32. Shear K, Frank E, Houck PR, Reynolds CF. Treatment of complicated grief: a randomized controlled trial. JAMA. 2005;293(21):2601-2608.

33. Thompson BE, Neimeyer RA, editors. Grief and the Expressive Arts: Practices for Creating Meaning. Abingdon: Routledge; 2014.

34. Gamino LA. Taking one's "game" to the next level: incorporating the expressive arts in grief counseling. J Constr Psychol. 2015;30(1):1-5.

35. American Art Therapy Association I. Newsletter, XK. Alexandria: American Art Therapy Association, INC; 2007, 23.

36. Potash JS, Ho AH, Chan F, Wang XL, Cheng C. Can art therapy reduce death anxiety and burnout in end-of-life care workers? A quasi-experimental study. Int J Palliat Nurs. 2014;20(5):233-240.

37. Levine SK. Poiesis: The Language of Psychology and the Speech of the Soul. London: Jessica Kingsley Pub; 1992.

38. Malchiodi CA. Art therapy and the brain. In: Malchiodi, ed. Handbook of Art Therapy. 2nd ed. New York The Guilford Press; 2003;17-24.

39. Kagin SL, Lusebrink VB. The expressive therapies continuum. Art Psychother. 1978;5(4):171-180.

40. Malchiodi CA. Embracing our mission. Art Ther. 1978;15(2):82-83.

41. McKissock MA, McKissock DR. Bereavement: a" natural disaster". Responses and adaptations. Med J Aust. 1991;154(10):677-681.

42. Malchiodi CA. Art and loss. Art Ther. 1992;9(3):114-118.

43. Torres C, Neimeyer RA, Neff ML. The expressive arts in grief therapy: an empirical perspective. In: Neimeyer R, Thompson BE, editors. Grief and the Expressive Arts: Practices for Creating Meaning. (Chap. 56). New York: Routledge; 2014:283-290.

44. Rosner R, Kruse J, Hagl M. A meta-analysis of interventions for bereaved children and adolescents. Death Stud. 2010;34(2):99-136. 
45. Uttley L, Scope A, Stevenson M, et al. Systematic review and economic modelling of the clinical effectiveness and cost-effectiveness of art therapy among people with non-psychotic mental health disorders. Health Technol Assess. 2015;19(18):1-120,v-vi.

46. Frattaroli J. Experimental disclosure and its moderators: a metaanalysis. Psychol Bull. 2006;132(6):823-865.

47. Honos-Webb L, Harrick EA, Stiles WB, Park CL. Assimilation of traumatic experiences and physical-health outcomes: cautions for the Pennebaker paradigm. Psychotherapy. 2000;37(4):307.

48. Field NP, Gal-Oz E, Bonanno GA. Continuing bonds and adjustment at 5 years after the death of a spouse. J Consult Clin Psychol. 2003;71(1):110.

49. Silverman PR, Nickman S, Worden JW. Detachment revisited: the child's reconstruction of a dead parent. Am J Orthopsychiatry. 1992;62(4):494.

50. Bonanno GA, Mihalecz MC, LeJeune JT. The core emotion themes of conjugal loss. Motiv Emot. 1999;23(3):175-201.

51. Attig T. The Heart of Grief. New York: Oxford; 2000.

52. Waskowic TD, Chartier BM. Attachment and the experience of grief following the loss of a spouse. Omega. 2003;47(1):77-91.

53. Thompson SC, Janigian AS. Life schemes: a framework for understanding the search for meaning. J Soc Clin Psychol. 1988;7(2-3): 260-280.

54. Currier JM, Holland JM, Coleman RA, Neimeyer RA. Bereavement following violent death: An assault on life and meaning. In: Stevenson RG, Cox GR, eds. Perspectives on Violence and Violent Death. Amityville, New York: Baywood Publishing Co; 2008:177-202.

55. Nadeau JW. Meaning making in family bereavement: a family systems approach. In: Stroebe MS, Hansson RO, Schut H, et al., editors. Handbook of Bereavement Research and Practice: Advances in Theory and Intervention. Washington, DC: American Psychological Association; 2008:329-347.

56. Park CL, Edmondson D, Fenster JR, Blank TO. Meaning making and psychological adjustment following cancer: the mediating roles of growth, life meaning, and restored just-world beliefs. J Consult Clin Psychol. 2008;76(5):863.

57. Davis CG, Nolen-Hoeksema S. Loss and meaning: how do people make sense of loss? Am Behav Sci. 2001;44(5):726-741.

58. Lichtenthal WG, Currier JM, Neimeyer RA, Keesee NJ. Sense and significance: a mixed methods examination of meaning making after the loss of one's child. J Clin Psychol. 2010;66(7):791-812.

59. Wheeler I. Parental bereavement: the crisis of meaning. Death Stud. 2010;25(1):51-66.

60. Coleman RA, Neimeyer RA. Measuring meaning: searching for and making sense of spousal loss in late-life. Death Stud. 2010;34(9):804-834.

61. Bonanno GA, Kaltman S. The varieties of grief experience. Clin Psychol Rev. 2001;21(5):705-734.

62. Doka KJ. Grief, multiple loss and dementia. Bereavement Care. 2010;29(3):15-20.

63. Worden JW. Grief Counseling and Grief Therapy. Third ed. New York: Springer; 2002.

64. Shapiro ER. Whose recovery, of what? Relationships and environments promoting grief and growth. Death Stud. 2007;32(1):40-58.

65. Burnett P, Middleton W, Raphael B, Martinek N. Measuring core bereavement phenomena. Psychol Med. 1997;27(01):49-57.

66. Hogan NS, Greenfield DB, Schmidt LA. Development and validation of the Hogan grief reaction checklist. Death Stud. 2001;25(1):1-32.

67. Prigerson HG, Maciejewski PK, Reynolds CF, et al. Inventory of Complicated Grief: a scale to measure maladaptive symptoms of loss. Psychiatry Res. 1995;59(1):65-79.

68. Faschingbauer TR, Zisook S, DeVaul R. The Texas revised inventory of grief. In: Zisook S, editor. Biopsychosocial Aspects of Bereavement. Washington, DC: American Psychiatric Press, Inc.; 1981:109-124.

69. American Art Therapy Association. What Is Art Therapy?. American Art Therapy Association; 2013. Available from: http://www.arttherapy. org/upload/whatisarttherapy.pdf. Accessed November 1, 2016.

70. Efland A. Art and Cognition: Integrating the Visual Arts in the Curriculum. New York: Teachers College Press; 2002.
71. Schut HA, De Keijser J, Van den Bout J, Stroebe MS. Cross-Modality Grief Therapy: description and assessment of a new program. J Clin Psychol. 1996;52(3):357-365.

72. Maier EH. Narrative Scrapbooking: Empathic Facilitation of Cocreated Stories for Bereaved and Nonspecific Adults in Supplemental Therapeutic Support Groups [ProQuest Dissertations and Theses Database; TX 6641222]. Palo Alto, Institute of Transpersonal Psychology; 2007.

73. Coar H. Using Mandalas to Support Grieving Female Adolescents: A Case Study [ProQuest Dissertations \& Theses Global]. CA, US: California State University; 2010.

74. Handler L, Habenicht D. The kinetic family drawing technique: a review of the literature. J Pers Assess. 1994;62(3):440-464.

75. Carew SA. The Psychological Effects of Art Therapy on Children Who Have Experienced Traumatic Grief [ProQuest Dissertations \& Theses Global; 305380457]. Muckleneuk, Pretoria, South Africa: University of South Africa; 2005.

76. Bates SM. Embodying the Soul's Pain: A Study of Memorial Tattoos and the Grieving Process [ProQuest Dissertations \& Theses Global]. CA, US: Institute of Transpersonal Psychology; 2010.

77. Ferszt GG, Hayes PM, DeFedele S, Horn L. Art therapy with incarcerated women who have experienced the death of a loved one. Art Ther. 2004;21(4):191-199.

78. Brodie S. Art Therapy and Adolescent Parental Bereavement: Case Study of a 14-Year-Old Girl [ProQuest Dissertations \& Theses Global; 304793556]. Montreal, Quebec, Canada: Concordia University; 2007.

79. Simon RM. The symbolism of style: art as therapy. Child Lang Teach Ther. 1992;8(2):224-225.

80. Finn CA. Helping students cope with loss: incorporating art into group counseling. J Spec Group Work. 2003;28(2):155-165.

81. Steer RA, Beck AT. Beck Anxiety Inventory. In: Zalaquett, Wood CP, eds. Evaluating stress: A book of resources. Lanham: Scarecrow Education; 1997:23-40.

82. Reynolds CR, Richmond BO. Revised Children's Manifest Anxiety Scale. Los Angeles: Western Psychological Services; 1985.

83. Beck AT, Steer RA, Brown GK. Beck Depression Inventory-II. San Antonio, TX: Psychological Corporation; 1996.

84. Moos RH, Moos BS. Family Environment Scale Manual. Sunnyville: Consulting Psychologists Press; 1994.

85. Achenbach TM, Rescorla L. Child Behavior Checklist. Florence, NJ Burlington; 2000.

86. Hightower AD, Spinell A, Lotyczewski BS. Teacher-Child Rating Scale (T-CRS) Guidelines. Rochester, NY: Primary Mental Health Project; 1989.

87. Springer JF, Phillips JL. Individual Protective Factors Index (IPFI): A Measure of Adolescent Resiliency. Saint Louis: Evaluation Management Training Associates Inc.; 1997.

88. Foa EB, Johnson KM, Feeny NC, Treadwell KR. The Child PTSD Symptom Scale: a preliminary examination of its psychometric properties. J Clin Child Psychol. 2001;30(3):376-384.

89. Horowitz M, Wilner N, Alvarez W. Impact of Event Scale: a measure of subjective stress. Psychosom Med. 1979;41(3):209-218.

90. Program for Prevention Research. Family Bereavement Program Documentation. Tempe, AZ: Arizona State University; 1999.

91. Goldberg DP, Hillier VF. A scaled version of the General Health Questionnaire. Psychol Med. 1979;9(01):139-145.

92. Wells NE. The Relationship between Grief Intervention Counseling and Resiliency in Elementary School-age Children [ProQuest Dissertations \& Theses Global; 304196074]. CA, US: University of San Francisco; 1994.

93. Herring J. Does PTSD Interfere in Reconciling Grief after Childhood Bereavement? An Evaluation of a Grief-Focused Group Intervention [ProQuest Dissertations \& Theses Global; 1458329148]. New York: St. John's University; 2013.

94. Webb-Ferebee KL. Expressive Arts Therapy with Bereaved Families [ProQuest Dissertations \& Theses Global; 304714629]. Denton: University of North Texas; 2001. 
95. Neimeyer RA, editor. Techniques of Grief Therapy: Assessment and Intervention. New York: Routledge; 2016.

96. Neimeyer RA, Burke LA, Mackay MM, van Dyke Stringer JG. Grief therapy and the reconstruction of meaning: from principles to practice. J Contemp Psychother. 2010;40(2):73-83.

97. Granek L. Grief as pathology: the evolution of grief theory in psychology from Freud to the present. Hist Psychol. 2010;13(1):46.

98. Stroebe M, van Son M, Stroebe W, Kleber R, Schut H, van den Bout J. On the classification and diagnosis of pathological grief. Clin Psychol Rev. 2000;20(1):57-75.

99. Bonanno GA, Wortman CB, Lehman DR, et al. Resilience to loss and chronic grief: a prospective study from preloss to 18 -months postloss. J Pers Soc Psychol. 2002;83(5):1150.

100. McIntyre BB. Art therapy with bereaved youth. J Palliat Care. 1990;6(1):16-25.

101. Lu L. "I Don't Know Where Is Me": Lost and Found in Art TherapyA Transcultural Approach Exploring Cultural Bereavement, Trauma, and Grief [ProQuest Dissertations \& Theses Global; 304784486]. Montreal: Concordia University; 2007.

102. Kalmanowitz D, Potash JS. Ethical considerations in the global teaching and promotion of art therapy to non-art therapists. Art Ther. 2010;37(1):20-26.

103. McNiff S. Art as Medicine: Creating a Therapy of the Imagination. Colorado: Shambhala Publications; 2013.

104. Kaiser D, Deaver S. Establishing a research agenda for art therapy: a Delphi study. Art Ther. 2013;30(3):114-121.

105. Spooner H. Embracing a full spectrum definition of art therapy. Art Ther. 2016;33(3):163-166.

106. Schut H, Stroebe MS, Van den Bout J, Terheggen M. The efficacy of bereavement interventions: determining who benefits. In: Henk S, editor. Handbook of Bereavement Research: Consequences, Coping, and Care. Washington, DC: American Psychological Association; 2001:705-737.

107. van der Houwen K, Schut H, van den Bout J, Stroebe M, Stroebe W. The efficacy of a brief internet-based self-help intervention for the bereaved. Behav Res Ther. 2010;48(5):359-367.

108. Deaver SP. What constitutes art therapy research? Art Ther. 2002;19(1): 23-27.

109. Feigelman W, Gorman BS, Jordan JR. Stigmatization and suicide bereavement. Death Stud. 2009;33(7):591-608.

110. Minton ME, Barron CR. Spousal bereavement assessment: a review of bereavement-specific measures. J Gerontol Nurs. 2008;34(8):34-48.

111. Neimeyer RA, editor. Techniques of Grief Therapy: Assessment and Intervention. New York: Routledge; 2016.

112. Neimeyer RA, Gillies JM, Milman E. Grief and meaning reconstruction inventory (GMRI). In: Neimeyer RA, editor. Techniques of Grief Therapy: Assessment and Intervention. (Chap. 9). New York: Routledge; 2016:59-64.
113. Crits-Christoph P, Baranackie K, Kurcias, et al. Meta-analysis of therapist effects in psychotherapy outcome studies. Psychother Res. 1991;1(2):81-91.

114. Baldwin SA, Murray DM, Shadish WR. Empirically supported treatments or type I errors? Problems with the analysis of data from group-administered treatments. J Consult Clin Psychol. 2005;73(5): 924.

115. Chilcote RL. Art therapy with child tsunami survivors in Sri Lanka. Art Therapy. 2007;24(4):156-162.

116. Hernandez JC. An evaluation of the footsteps program: The effectiveness of art and group therapy for children who have experienced a significant loss [ProQuest Dissertations \& Theses Global; 305346163]. CA, US: California State University; 2005.

117. Hornbeck AK. Grieving the loss of a child, parent, or spouse through group art therapy [ProQuest Dissertations \& Theses Global; 305057770]. Ohio, US: Ursuline College; 2004.

118. Hubnik MA. Children's drawings of concepts of death as related to cognitive developmental level [ProQuest Dissertations \& Theses Global; 238194478]. Texas, US: Texas Woman's University; 2000.

119. Isis PD. A qualitative study demonstrating the impact of the expressive therapies on the grief process for three women through case studies [ProQuest Dissertations \& Theses Global; 305459247]. Ohio, US: Union Institute and University; 2002.

120. Kerewsky SD. The AIDS memorial quilt: Personal and therapeutic uses. Arts Psychother. 1997;24(5):431-438.

121. Kohut M. Making art from memories: Honoring deceased loved ones through a scrapbooking bereavement group. Art Therapy. 2011;28(3):123-131.

122. Kwan GP. The Chinese brush stroke experience in bereavement counseling [ProQuest Dissertations \& Theses Global; 1513246490]. Massachusetts, US: Lesley University; 2011.

123. Lang LA. Expressions of grief: Art therapy used as an intervention in the treatment of bereaved adolescents [ProQuest Dissertations \& Theses Global]. Ohio, US: Ursuline College; 1992.

124. Mango C. EMMA: Art therapy illustrating personal and universal images of loss. OMEGA (Westport). 1992;25(4):259-269.

125. Peiffer M. Drawings as an effective tool in understanding and working with grief: A case study approach [ProQuest Dissertations \& Theses Global; 89202165]. Alberta, Canada: University of Alberta; 1993.

126. Phillips K. Healing images: A journey through the grieving process of an adolescent with delinquent behaviors [ProQuest Dissertations \& Theses Global; 304570750]. Ohio, US: Ursuline College; 1999.

127. Serazin LE. Gallery of grief: Utilizing art therapy to reduce future risk in bereaved children [ProQuest Dissertations \& Theses Global; 238156836]. Ohio, US: Ursuline College; 1996.

128. Simon R. Bereavement art. Art Ther (Alex). 1981;20(4):135-143.
Psychology Research and Behavior Management

\section{Publish your work in this journal}

Psychology Research and Behavior Management is an international, peerreviewed, open access journal focusing on the science of psychology and its application in behavior management to develop improved outcomes in the clinical, educational, sports and business arenas. Specific topics covered in the journal include: Neuroscience, memory and decision making; Behavior

\section{Dovepress}

modification and management; Clinical applications; Business and sports performance management; Social and developmental studies; Animal studies. The manuscript management system is completely online and includes a very quick and fair peer-review system, which is all easy to use. Visit http://www. dovepress.com/testimonials.php to read real quotes from published authors. 